\title{
Annette Becker, La Grande Guerre d'Apollinaire. Un poète combattant
}

\section{Elisa Borghino}

\section{(2) OpenEdition}

1 Journals

\section{Edizione digitale}

URL: http://journals.openedition.org/studifrancesi/573

DOI: $10.4000 /$ studifrancesi.573

ISSN: 2421-5856

\section{Editore}

Rosenberg \& Sellier

\section{Edizione cartacea}

Data di pubblicazione: 1 aprile 2015

Paginazione: 186

ISSN: 0039-2944

\section{Notizia bibliografica digitale}

Elisa Borghino, «Annette Becker, La Grande Guerre d'Apollinaire. Un poète combattant », Studi Francesi [Online], 175 (LIX | I) | 2015, online dal 01 avril 2015, consultato il 18 septembre 2020. URL : http:// journals.openedition.org/studifrancesi/573 ; DOI : https://doi.org/10.4000/studifrancesi.573

Questo documento è stato generato automaticamente il 18 settembre 2020.

\section{(c) $(7)$}

Studi Francesi è distribuita con Licenza Creative Commons Attribuzione - Non commerciale - Non opere derivate 4.0 Internazionale. 


\title{
Annette Becker, La Grande Guerre d'Apollinaire. Un poète combattant
}

\author{
Elisa Borghino
}

\section{NOTIZIA}

ANNETTE BECKER, La Grande Guerre d'Apollinaire. Un poète combattant, Paris, Tallandier, 2014 («Texto»), pp. 267.

1 Annette Becker è membro dell'Institut Universitaire de France e professoressa all'Université Paris-Ouest Nanterre. Specialista di violenze estreme e culture belliche, la storica ripercorre con vivacità e audacia gli anni della Grande Guerra, permettendoci di intraprendere un viaggio singolare alla scoperta di un poeta fiero di essere diventato soldato.

2 Passo passo, ritroviamo Guillaume Apollinaire alle prese con le tappe più significative della sua vita di uomo e d'artista, dall'arruolamento nell'estate del 1914 fino alla morte avvenuta il 9 novembre 1918. La noia dell'esperienza militare, la paura in prima linea, lo smarrimento in seguito alla ferita alla testa nel 1916 riemergono nella biografia letteraria di uno tra i più grandi poeti della modernità.

3 Contrariamente a quanto si potrebbe pensare, negli scritti scelti e proposti dall'autrice non leggiamo l'apologia del primo dei due terribili conflitti mondiali, quanto l'incredibile forza della vita nella morte, di cui lo stesso Apollinaire si fa icona nel momento decisivo del suo trauma alla testa.

4 Anche se violenza, crudeltà e sofferenza sono i perni attorno ai quali ruota la biografia di Annette Becker, le vicende raccontate permettono prima di evocare e poi di approfondire, tra l'altro, temi quali l'occupazione del Nord della Francia, il fronte, il patriottismo, l'antisemitismo e la xenofobia. Attraverso le attente osservazioni del poeta ricostruiamo così nel dettaglio il «dietro le quinte» del Grande conflitto mondiale, dallo scoppio di bombe e siluri fino alla nascita di un vero e proprio «artigianato» delle trincee con la lucidatura degli anelli. 
5 Poeta e critico d'arte, inserito in una cerchia di amici intellettuali, artisti, musicisti, nella sua esperienza di combattente ferito, Wilhelm de Kostrowitzky si rivela uomo dalle molteplici identità, scrittore dal duplice nome, soldato dal nome particolare. Di madre polacca e padre italiano, Apollinaire mostra un grande attaccamento alla Francia e una certa diffidenza nei confronti della Germania. Con la sua storia personale si intrecciano evidentemente le vicende di Picasso e Cendrars, Duchamp, Breton, Éluard, ma anche le avventure di tanti personaggi comuni che hanno condiviso la sua quotidianità, riprodotta in innumerevoli scritti, disegni e registrazioni sonore, trattati come delle fonti nuove ed indispensabili alla conoscenza di un periodo storico tanto significativo.

6 Studiare Apollinaire sotto questa nuova luce significa quindi ricostruire la sua battaglia, costituita dalle sue certezze, dalle sue ansie e dai suoi rifiuti, per poi contestualizzarla in una guerra universale, che appartiene a tutti. La traduzione dell'esperienza dell'arruolamento nella produzione del poeta, il ricordo del suo impegno militare e della sua ferita toccheranno generazioni di scrittori francesi, e non solo, che si interrogheranno sul reale significato della Grande Guerra. 